\title{
Bach1 Deficiency Ameliorates Hepatic Injury in a Mouse Model
}

\author{
Akio Iida, ${ }^{1}$ Koji Inagaki, ${ }^{1}$ Akira Miyazaki, ${ }^{1}$ Fumihiko Yonemori, ${ }^{1}$ Etsuro Ito ${ }^{2}$ and \\ KAZUHIKO IGARASHI \\ ${ }^{1}$ Japan Tobacco Inc., Central Pharmaceutical Research Institute, Osaka, Japan \\ ${ }^{2}$ Department of Pediatrics, Hirosaki University School of Medicine, Hirosaki, Aomori, Japan \\ ${ }^{3}$ Department of Biochemistry, Tohoku University Graduate School of Medicine, Sendai Japan
}

\begin{abstract}
Bach1 is a basic region-leucine zipper (bZip) protein that forms heterodimers with the small Maf proteins and functions as a repressor of gene expression. One of the target genes of Bach1 is Hmox-1 that encodes heme oxygenase-1 (HO-1). HO-1 degrades heme into carbon monoxide (CO), biliverdin, and iron. HO-1 is strongly induced by various stresses as well as its substrate heme, and protects cells and tissues against insults through diverse cytoprotective functions of the reaction products $\mathrm{CO}$ and biliverdin. Bach1deficiency in mice leads to higher expression of Hmox-1 in various tissues. Here we investigated the effects of Bach1-deficiency in mice on tissue injuries: hepatic injury induced by D-galactosamine (GalN) and lipopolysaccharide (LPS), and mouse paw edema induced by carrageenin, polysaccharide derived from various seaweeds. Bach1-deficiency suppressed induction of plasma alanine aminotransferase (ALT) and aspartate aminotransferase (AST) activities in response to the GalN/LPS-treatment. However, production of tumor necrosis factor alpha (TNF- $\alpha$ ) and nitric oxide (NO), both being cytotoxic mediators in LPSinduced hepatic injury, in Bach1-deficient mice and their peritoneal macrophages was similar to wild type controls. In contrast, Bach1-deficiency did not affect extent of mouse paw edema induced by carrageenin, which enhances vascular permeability by activating kinin release. These results indicate that Bach1 plays an inhibitory role in the cytoprotection of LPS-induced liver injury but not in the kinin-mediated inflammatory edema. The inhibitory role for Bach1 may stem from its activity to repress gene expression including HO-1. transcription factor; oxidative stress; heme oxygenase; Maf; liver.
\end{abstract}

Tohoku J. Exp. Med., 2009, 217 (3), 223-229. (C) 2009 Tohoku University Medical Press

Bach1 is a basic region-leucine zipper (bZip) transcription factor that forms heterodimers with the small Maf proteins. The resulting Bach1 heterodimers bind to the Maf recognition elements (MAREs) to repress transcription (Oyake et al. 1996; Igarashi et al. 1998; Ogawa et al. 2001; Sun et al. 2002; Sun et al. 2004). Other bZip transcription factors such as NF-E2 related factor (Nrf)1 and Nrf2, distantly related to Bach1 (Amoutzias et al. 2007), also form heterodimers with the small Maf proteins, bind to MARE, and activate transcription. As such, MARE-dependent transcription is finely tuned by both repressors and activators (Motohashi et al. 2002; Igarashi and Sun 2006). The balance of repression and activation is modulated in part by heme: direct binding of heme to Bach1 inhibits the DNA binding activity of Bach1/small Maf heterodimer and induces nuclear export of Bach1 (Ogawa et al. 2001; Sun et al. 2002; Suzuki et al. 2004). Furthermore, heme induces polyubiquitination and subsequent degradation of Bach1 (Zenke-Kawasaki et al. 2007). MARE or MARE-like sequences are present in regulatory regions of various genes that are related to heme, oxidative stress response, and xenobiotics metabolism (Kyo et al. 2004). One of the well characterized target genes of Bach1 is Hmox-1 that encodes heme oxygenase-1 (HO-1). Expression of Hmox-1 in cultured cells or in organs is very low under normal conditions due to Bach1-mediated repression but is highly induced by its substrate heme, oxidative stress, or other diverse stimuli such as cytokines, heavy metals and heat shock (Shibahara et al. 1985, 1987; Alam et al. 1989; Keyse and Tyrrell 1989; Taketani et al. 1989). Hmox-1 is constitutively expressed at higher levels in many tissues of Bachl-deficient mice, indicating that Bach 1 acts as a negative regulator of transcription of Hmox-1 (Sun et al. 2002; Omura et al. 2005).

HO-1 catalyzes oxidative degradation of heme, generating iron, carbon monoxide, and biliverdin, which is rapidly reduced to bilirubin. Carbon monoxide, biliverdin, and bilirubin possess antioxidant and anti-inflammatory actions (Baranano et al. 2002; Otterbein et al. 2003). Consistent with their protective actions, induction of HO-1 under diverse stress conditions have been shown to protect cells and tissues. For example, HO-1 protects cultured fibroblasts and endothelial cells from TNF-induced apoptosis

Received November 25, 2008; revision accepted for publication February 12, 2009.

Correspondence: Kazuhiko Igarashi, Department of Biochemistry, Tohoku University Graduate School of Medicine, Sendai 980-8575, Japan.

e-mail: igarak@m.tains.tohoku.ac.jp 
(Brouard et al. 2000; Petrache et al. 2000). In addition, HO-1 induction confers protective action in various models of organ injuries in vivo (Alam et al. 1989; Choi and Alam 1996; Yang et al. 1999; Chen et al. 2000; Shimizu et al. 2000; Akagi et al. 2002; Nakahira et al. 2003; Sass et al. 2003; Dorman et al. 2004). Conversely, the physiological importance of HO-1 encoded by Hmoxl gene has been shown by the phenotypic consequences of the Hmoxldeficient mice that show a hypersensitivity to the oxidative damage and cytotoxicity caused by hemin and hydrogen peroxide (Poss and Tonegawa 1997a, 1997b) and by a patient with HMOX1-deficiency (Yachie et al. 1999). Therefore, there is a possibility that Bach1 is an inhibitory factor of cell and tissue defense systems as a repressor of Hmox- 1 and/or other genes. Consistent with this idea, genetic ablation of Bach1 in mice results in reduction of tissue damage after ischemic-reperfusion injury of heart (Yano et al. 2006) and reduction of arteriosclerosis after cuff injury (Omura et al. 2005).

To further understand the function of Bach1 in protective responses against various stresses, we examined the effects of Bach1 deficiency on galactosamine (GalN)/ lipopolysaccharide (LPS)-induced liver injury, which is known to be alleviated by induction of HO-1 (Sass et al. 2003). It was reported previously that LPS-induced hepatic injury is caused by hepatocyte apoptosis mediated by tumor necrosis factor alpha (TNF- $\alpha$ ) and nitric oxide (NO) (Lehmann et al. 1987; Morikawa et al. 1999; Sass et al. 2003; Wolf et al. 2005). Thus, we compared LPS-induced TNF- $\alpha$ and NO production in Bachl-deficient and control mice. Because HO-1 suppresses inflammatory response to carrageenin (Willis et al. 1996), we also examined the effect of Bach1-deficiency in carrageenin-induced mouse paw edema as an inflammation model.

\section{Materials And Methods}

\section{Reagents}

Galactosamine (GalN) was from Wako Pure Chemical Industries, Ltd. (Osaka, Japan). Lipopolysaccharide (LPS) was from Sigma (St Louis, MO). Hyperfilm ECL and ECL plus detection reagent were from Amersham Biosciences, Inc. (Buckinghamshire, England). Horseradish peroxidase-coupled goat anti-rabbit IgG was from Kirkegaard \& Perry Laboratories, Inc. (Gaithersburg, Maryland). $\lambda$-Carrageenin (Picnin A) was from Zushikagaku Laboratory (Kanagawa, Japan).

\section{Animals}

Generation of $\mathrm{Bachl}^{-/}$mice on a C57BL/6J background has been reported elsewhere (Sun et al. 2002). Bach1 ${ }^{+/+}, \mathrm{Bachl}^{+/-}$and Bach $1^{-/}$mice aged 7 -12 weeks were kept on a 12-h light / dark cycle with free access to food and sterile water. All the experiments received prior approval from the committee for the human care and use of animals of our laboratory (Japan Tobacco Inc., Central Pharmaceutical Research Institute), in accordance with the Standards Relating to the Care and Management of Experimental Animals (Notification No. 6, March 27, 1980, of the Prime Minister's Office of Japan).

\section{GalN/LPS-induced liver injury model}

Mice were injected intraperitoneally (i.p.) with GalN (500 mg/ $\mathrm{kg})$ and LPS $(3 \mu \mathrm{g} / \mathrm{kg})$. Heparinized blood was obtained from the orbital sinus of the mice at 1 and 6 hours after GalN/LPS injection. Blood plasma was separated from heparinized whole blood by centrifugation at $2000 \times g$ for 3 minutes at $4^{\circ} \mathrm{C}$. The activities of plasma ALT and AST at 6 hours after GalN/LPS injection, the marker enzymes of liver injury, were measured with Monarch (Instrumentation Laboratory, Lexington MA). Plasma concentration of TNF- $\alpha$ at 1 hour after GalN/LPS injection was measured with commercial murine TNF- $\alpha$ ELISA kit (Quantikine M; R\&D Systems, Mineapolis, MN).

\section{Macrophage culture and LPS stimulation}

Resident macrophages were obtained from the mice by lavage of the peritoneal cavity with $5 \mathrm{ml}$ of sterile phosphate buffer solution containing $10 \mathrm{U} / \mathrm{ml}$ heparin. Cells were washed three times with RPMI 1640 containing $10 \%$ fetal bovine serum at $4{ }^{\circ} \mathrm{C}$. The macrophages at $2 \times 10^{6}$ cells $/ \mathrm{ml}$ were incubated in RPMI 1640 medium in $450 \mu \mathrm{l} /$ well in a 24 -well tissue culture plate. Macrophages were stimulated with LPS solution (final concentration; $1 \mu \mathrm{g} / \mathrm{ml}$ ). All cell cultures were maintained at $37^{\circ} \mathrm{C}$ in a humidified incubator containing $5 \% \mathrm{CO}_{2}$ in air. The results of preliminary investigations showed that secretion of TNF- $\alpha$ and NO from macrophages stimulated by LPS became saturated after 12-24 hours (data not shown). Therefore, culture fluids were collected at 19 hours after incubation. TNF- $\alpha$ concentration of culture supernatants were measured with commercial murine TNF- $\alpha$ ELISA kit. NO was measured as its end product, nitrite, by using Griess reagent as described previously (Wang et al. 1994). The supernatant $(10 \mu 1)$ diluted with phosphate buffer solution (40 $\mu 1)$. The diluted supernatant was mixed with $50 \mu 1$ of Griess reagent for 10 minutes, and the absorbance at $570 \mathrm{~nm}$ was measured in a microplate reader. The concentration of nitrite in the samples was determined with reference to a sodium nitrite standard curve. The data represents the mean of triplicate determinations \pm SEM. The adherent cells were lysed on ice with lysis buffer composed of 50 $\mathrm{mmol} / \mathrm{L}$ Tris $/ \mathrm{HCl}$ (pH 6.8), $10 \%$ glycerol and $1 \%$ SDS at $4{ }^{\circ} \mathrm{C}$ for 30 minutes. These lysis samples were assessed with western blot analysis described below.

\section{Western Blot Analysis}

Insoluble materials in the lysis samples described above were removed by centrifugation at $15,000 \times \mathrm{g}$ at $4^{\circ} \mathrm{C}$ for 10 minutes. The supernatants $(1 \mathrm{mg}$ protein/ml) were boiled in SDS-PAGE sample buffer for 3 minutes. After a brief centrifugation, the supernatants (20 $\mu 1 /$ lane) were separated by SDS-PAGE and then electroblotted onto nitrocellulose membrane. The blots were blocked with $3 \%$ skim milk in PBS at room temperature for 1 hour and then incubated with primary anti-HO-1 antibody (Stressgen) at $1: 2000$ at room temperature for 1 hour. After washing with PBS containing 0.1\% Tween 20, the blots were probed with secondary antibody (horseradish peroxidasecoupled goat anti-rabbit IgG at $1: 5000$ ) at room temperature for 1 hour. After a second wash, the blots were exposed to Hyperfilm ECL and ECL plus detection reagent to enable visualization of phosphotyrosine-containing proteins.

\section{Carrageenin-Induced Paw Edema}

Right hind paw of mouse was measured by plethysmometer (TK-101; Unicom Inc., Chiba, Japan) $2 \mathrm{~h}$ before Carrageenin inoculation. Carrageenin was dissolved in saline by incubation for $24 \mathrm{~h}$ at 
$4^{\circ} \mathrm{C}$ to make up $1 \%$ solution and inoculated subcutaneously at a volume of $50 \mu 1$ at foot pad of the right hind paw. At 2, 3, 5, 24 hours after carrageenin injection, paw volume was measured and compared with predosing value, and the edema formation of each mouse was determined. All the measurements were performed in a blind manner. Data were calculated as percentage of increase of the paw volume by comparing pre- and post-carrageenin injection.

\section{Statistical analysis}

Data are expressed as mean \pm SEM. The statistical significance was determined by Student's $t$ test or Aspin-welch $t$ test.

\section{Results}

Effects of Bach1-deficiency on GalN/LPS-induced liver injury

Combined injection of GalN and LPS causes massive liver injury due to apoptotic cell death (Morikawa et al. 1996). We compared the effects of Bachl-deficiency on GalN/LPS-induced liver injury using Bachl ${ }^{+/}$, Bachl $^{+/-}$and Bach $^{-/-}$mice. Injection of GalN/LPS significantly increased plasma ALT and AST activities in $\mathrm{Bachl}^{+/+}$mice that reflected liver injury (Fig. 1A and B). Release of ALT and AST activities after GalN/LPS treatment was significantly suppressed in $\mathrm{Bach}^{-/-}$mice. Interestingly, it was also reduced to some extent in $B a c h 1^{+/}$mice. Considering that LPS-induced cytotoxicity is mainly mediated by TNF- $\alpha$ (Lehman et al. 1987; Tiegs et al. 1989; Morikawa et al. 1996), we next examined plasma levels of TNF- $\alpha$ (Fig. 1C). While the level of TNF- $\alpha$ in wild-type mice sera was 60-70 $\mathrm{pg} / \mathrm{ml}$ without any treatment, it increased at 1 hour after GalN/LPS injection and then returned to basal level by 6 hours (data not shown). Plasma concentration of TNF- $\alpha$ in Bach $^{-1}$ mice similarly increased after injection of GalN/ LPS. No significant change in viability of mice was observed.

Bach1-deficiency does not affect LPS-induced TNF- $\alpha$ and NO production in macrophages

Macrophages produce proinflammatory cytokines including TNF- $\alpha$ and IL-6 in response to LPS. To investi-

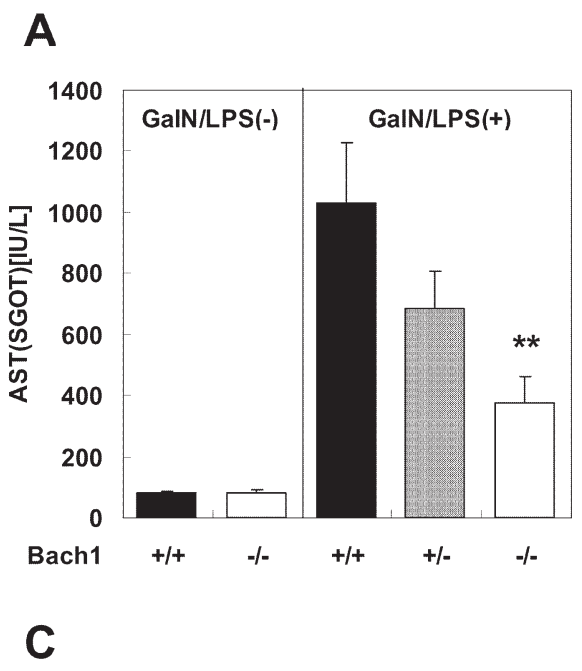

B
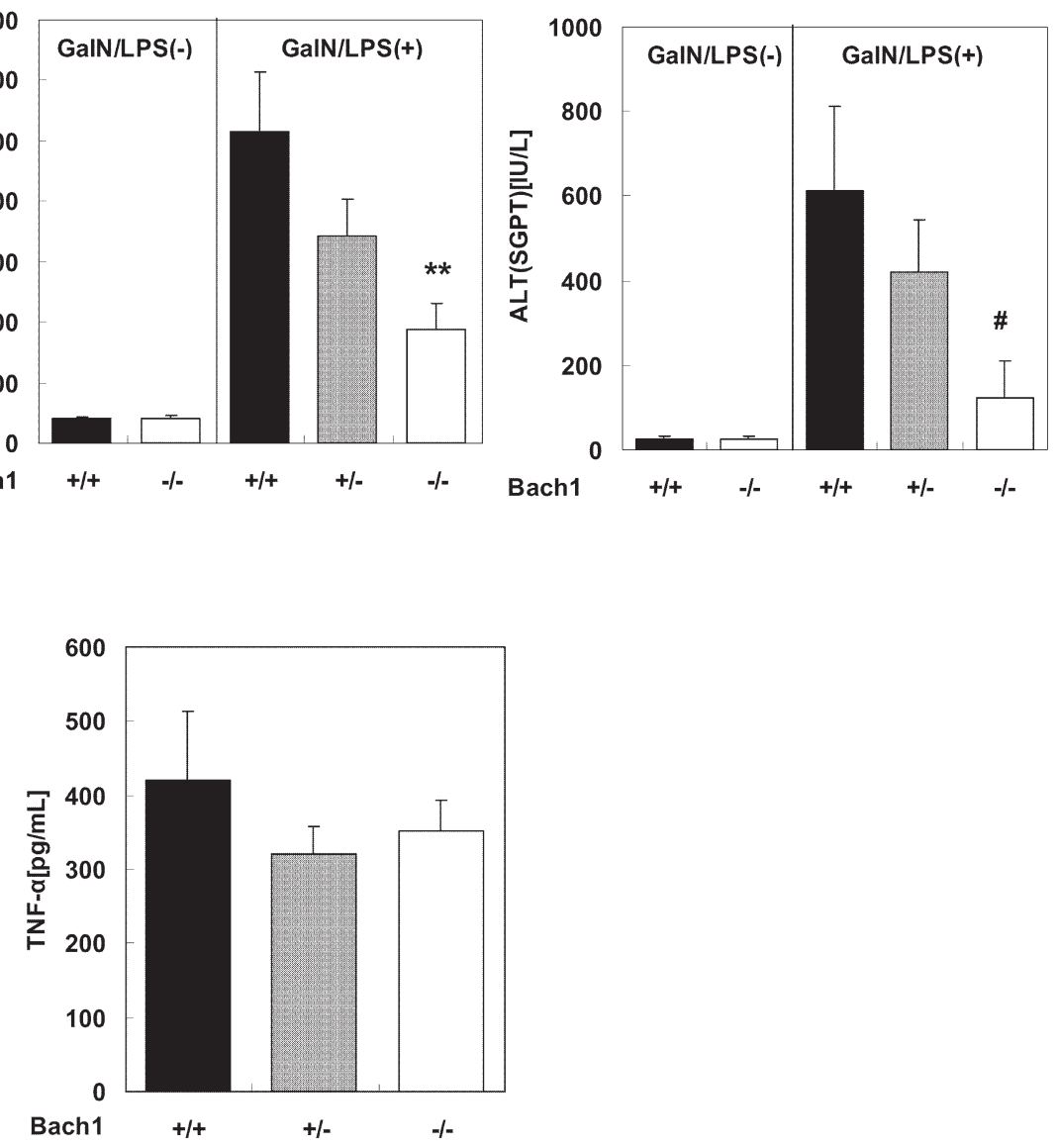

Fig. 1. Effects of GalN/LPS injection on plasma AST, ALT and TNF- $\alpha$ levels in control and Bach $1^{-/}$mice.

(A and B) The activities of plasma aminotransferase (ALT and AST) at 6 hours after GalN/LPS injection. Each value

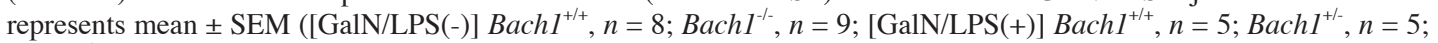
$\left.B a c h 1^{--}, n=6\right)$. (C) Plasma concentration of TNF- $\alpha$ at 1 hour after GalN/LPS injection. Each value represents mean \pm $\operatorname{SEM}\left(\mathrm{Bachl}^{+/+}, n=5 ; \mathrm{Bachl}^{+/}, n=5 ; \mathrm{Bachl}^{-/}, n=6\right)$. Statistical analysis was performed by Student's $t$ test $(* *, p<0.01)$ or by Aspin-welch $t$ test $(\#, p<0.05)$ v.s. control mice. 


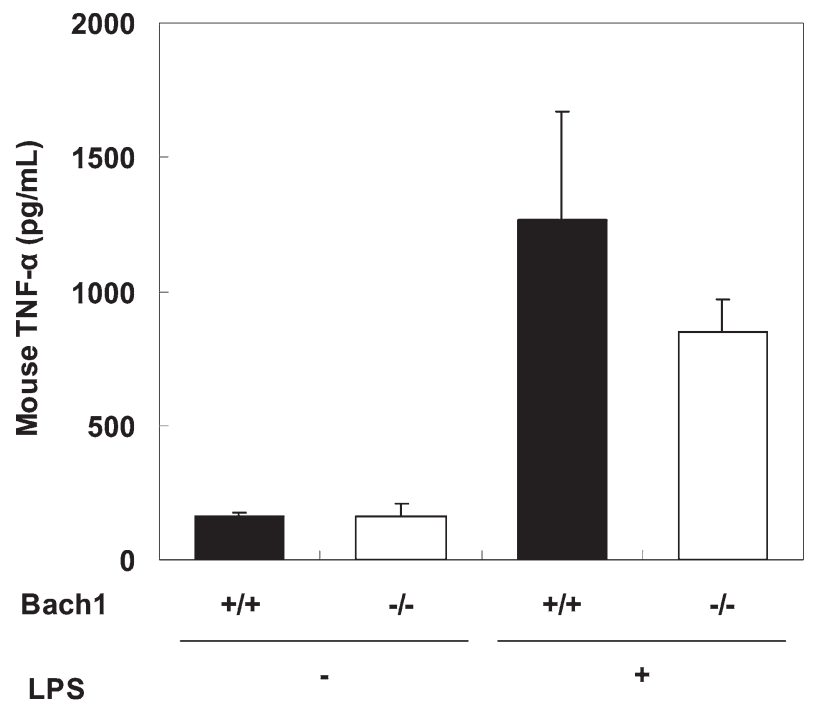

Fig. 2. TNF- $\alpha$ production of LPS-stimulated macrophage from peritoneal cavity in control and $\mathrm{BaCh}^{-/ 2}$ mice. Resident macrophages were obtained from the mice by lavage of the peritoneal cavity. Both macrophages were stimulated with LPS solution (final concentration; $1 \mu \mathrm{g} / 1$ $\mathrm{ml})$. Culture fluids were collected at 19 hours after incubation. TNF- $\alpha$ concentration of culture supernatants was measured with commercial murine TNF- $\alpha$ ELISA kit. Each value represents mean \pm SEM using three mice for each group.

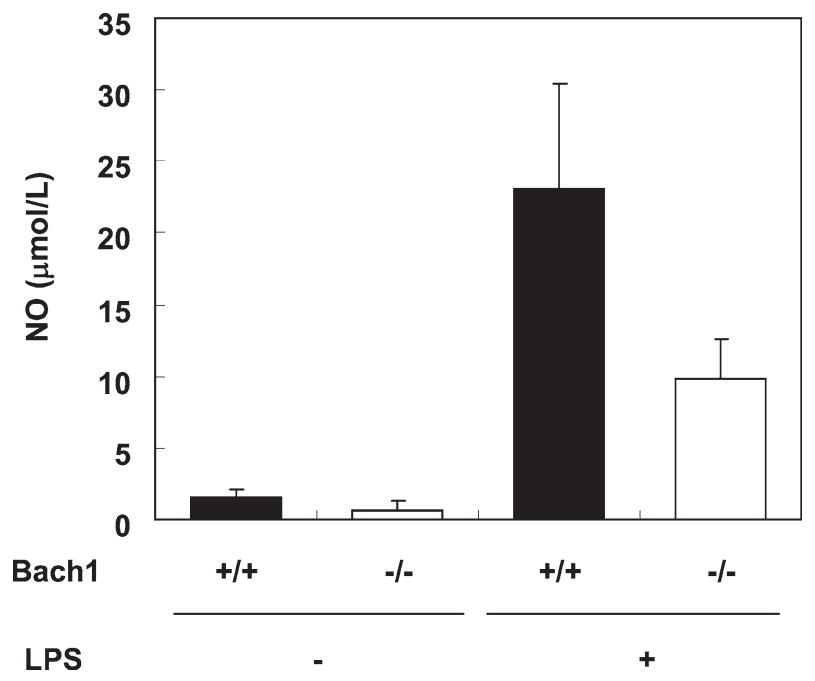

Fig. 3. NO production of LPS-stimulated macrophage in control and $\mathrm{Bachl}^{-/}$mice.

Macrophages were stimulated with LPS as in Fig. 2. NO was measured as its end product, nitrite, by using Griess reagent. Each value represents mean \pm SEM using three mice for each group.

\section{Bach1 +/+ Bach1 -/- \\ STD - $\quad$ LPS - $\quad$ LPS}

Fig. 4. HO-1 protein expression in control and $\mathrm{Bach}^{-/-}$mice macrophage after LPS-stimulation. Western blotting analysis for HO-1 in macrophage from peritoneal cavity of control and Bach $1^{-/}$mice after LPS-stimulation. Left lane (STD) is the molecular-weight marker.

gate the mechanisms of reduction of plasma ALT and AST by Bachl-deficiency in GalN/LPS-induced liver injury, we assessed the role of Bach1 in the response to LPS in vitro using peritoneal macrophages isolated from $\mathrm{Bachl}^{+/+}$and $B a c h 1^{-1-}$ mice. Stimulation with LPS markedly increased TNF- $\alpha$ secretion from macrophages from Bachl $^{+/+}$and $B a c h 1^{-1-}$ mice without any significant difference (Fig. 2).

LPS is known to induce NO production in macrophages (Lee et al. 2004). It was suggested previously that NO may participate in the development of liver injury (Morikawa et al. 1999). To examine whether Bach1 is involved in the production of $\mathrm{NO}$ in macrophages, isolated macrophages were stimulated with or without LPS, and levels of NO were determined. The basal levels of NO production were comparable in control and $\mathrm{BaCh}^{-/}$macrophages (Fig. 3). When stimulated with LPS, NO production was strongly induced in both macrophages, with no significant difference (Fig. 3). Since there is no report regarding HO-1 expression in Bachl-deficient macrophages, we examined LPS-induced HO-1 expression in peritoneal macrophages from $\mathrm{Bachl}^{+/+}$and control mice. Stimulation with LPS ex vivo increased HO-1 expression in $\mathrm{Bachl}^{+/+}$macrophages (Fig. 4). In contrast, HO-1 expression in macrophages from $\mathrm{Bachl}^{-/}$mice was much higher than those from $\mathrm{Bachl}^{+/+}$ mice even without LPS stimulation. Thus, it remains possible that overexpressed HO-1 modulates functions of Bach1deficient macrophages other than the production of TNF- $\alpha$ and NO.

Effect of Bach1-deficiency on carrageenin - induced paw edema

As is the case of GalN/LPS-induced liver injury model, 


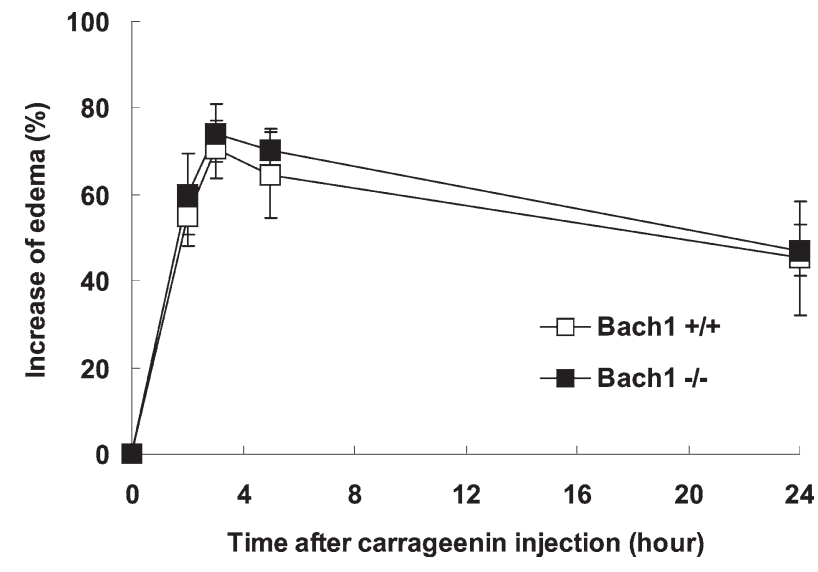

Fig. 5. Carrageenin-induced paw edema in control and Bachl $^{-1-}$ mice.

Paw volume was measured at 2, 3,5 and 24 hours after carrageenin injection in control (open square) and Bach $^{-/-}$(closed square) mice. Data were calculated as percentage of increase of the paw volume by comparing pre- and post-carrageenin injection and shown as the mean \pm SEM of five mice per group.

carrageenin-induced pleurisy is suppressed by induction of HO-1 (Willis et al. 1996). Thus, we next tested the effect of Bach1-deficiency in carrageenin-induced mouse paw edema as an inflammation model. However, there was no obvious difference in the progression of edematous injury between the two genotypes (Fig. 5). Thus, Bach1 may not be involved in the regulation of edematous response.

\section{Discussion}

Up-regulation of HO-1 by cobalt protoporphyrin is known to protect mice from apoptotic liver damage induced by GalN/LPS injection (Sass et al. 2003). In the present study, we examined effect of genetic ablation of Bach1 in this injury model system and found that Bach1 plays an inhibitory role in the protective response to this particular inflammatory stress in vivo. Specifically, induction of ALT and AST activities in blood was slightly suppressed in $\mathrm{Bach}^{+/-}$mice, and more suppressed in $\mathrm{Bach}^{-/-}$mice. Previously it was reported that LPS-induced liver injury is caused by hepatocyte apoptosis, mediated mainly by TNF- $\alpha$ (Morikawa et al. 1999). However, plasma TNF- $\alpha$ concentrations did not differ significantly between $\mathrm{Bachl}^{+/+}$and $\mathrm{Bachl}^{-/-}$mice. Furthermore, macrophages isolated from $\mathrm{Bach}^{-/-}$mice produced similar levels of TNF- $\alpha$ compared to control macrophages when stimulated with LPS in vitro. Although we can not rule out the possibility that other changes in macrophages could potentially affect apoptosis of hepatic cells, Bach1-deficiency may affect hepatocyte function in a cell-autonomous manner as discussed below.

Because HO-1 is expressed at much higher levels in liver (Sun et al. 2002) and macrophages (this study) of Bach1-deficient mice, the observed cytoprotective effect of Bach1 ablation may involve HO-1 overexpression in these cells. The increased HO-1 expression caused by Bachl- deficiency is expected to lead to degradation of heme and generation of $\mathrm{CO}$, ferrous iron, and biliverdin, which is rapidly reduced to bilirubin. $\mathrm{CO}$ is associated with inhibition of cell injury and vascular dilatation (Otterbein et al. 2003; Sass et al. 2003) and bilirubin exerts protection against oxidative cellular damage (Clark et al. 2000). While heme induces increased vascular permeability, adhesion molecule expression, and leukocyte recruitment, HO-1 antagonizes the heme-induced inflammation (Balla et al. 1991; Wagener et al. 2001). When taken together, it is conceivable that the protective effects caused by Bachl-deficiency in GalN/LPSinduced liver injury model reflect a composite mode of Bach1 action in hepatic cells and other cells including macrophages. It will be important to elucidate this complex network of cytoprotective responses at multiple levels.

Our previous (Omura et al. 2005; Yano et al. 2006) and current observations suggest that Bach1 inhibits cell and tissue survival in response to diverse stresses. Obvious enigma is whether Bach1 plays a role that allows natural selection inasmuch as natural selection usually favors a system for survival. Considering that heme is involved in a variety of biological events by modulating the function or the state of heme proteins (Furuyama et al. 2007), the primary function of Bach1 may reside in the regulation of heme homeostasis. Bach1 may also play beneficial roles as well in stress responses, which may have eluded our analysis thus far.

In contrast to the GalN/LPS-induced liver injury model, there was no protective effect of Bachl-deficiency in carrageenin-induced paw edema. Carrageenin, a waterextractable polysaccharide obtained from various seaweeds, induces macrophage accumulation in fluid exudates from subcutaneous chambers in dogs (Hou et al. 2004). Carrageenin activates kinin release and induces kinin B1 receptor (Campos et al. 1996; Decarie et al. 1996; Ni et al. 2003). Bradykinin, one of kinins, enhances vascular permeability and then causes inflammatory edema. It also activates phospholipase A2 (PLA2), enhancing PGE2 production which then enhances vascular permeability and vasodilation. Thrombin can act as an inflammatory mediator in this model (Cirino et al. 1996). Bach1 may not be related to these inflammatory mediators and to edematous response.

In conclusion, the results of this study suggest that Bach1 regulates the response of hepatic cells to inflammatory stresses. Taken together with its augmenting role in ischemic reperfusion injury of heart and atherosclerosis (Omura et al. 2005; Yano et al. 2006), inhibition of Bach1 may provide new therapeutic approaches toward various diseases.

\section{Acknowledgements}

We thank H. Suzuki, J. Sun, A. Muto and S. Omura for technical assistance. This work was supported in part by Grantsin-aid from the Ministry of Education, Science, Sport, and Culture of Japan. 


\section{References}

Akagi, R., Takahashi, T. \& Sassa, S. (2002) Fundamental role of heme oxygenase in the protection against ischemic acute renal failure. Jpn. J. Pharmacol., 88, 127-132.

Alam, J., Shibahara, S. \& Smith, A. (1989) Transcriptional activation of the heme oxygenase gene by heme and cadmium in mouse hepatoma cells. J. Biol. Chem., 264, 6371-6375.

Amoutzias, GD., Veron, AS., Weiner, J., 3rd, Robinson-Rechavi, M., Bornberg-Bauer, E., Oliver, SG. \& Robertson, DL. (2007) One billion years of bZIP transcription factor evolution: conservation and change in dimerization and DNA-binding site specificity. Mol. Biol. Evol., 24, 827-835.

Balla, G., Vercellotti, GM., Muller-Eberhard, U., Eaton, J. \& Jacob, HS. (1991) Exposure of endothelial cells to free heme potentiates damage mediated by granulocytes and toxic oxygen species. Lab, Inves., 64, 648-655.

Baranano, D.E., Rao, M., Ferris, C.D. \& Snyder, S.H. (2002) Biliverdin reductase: a major physiologic cytoprotectant. Proc. Natl. Acad. Sci. USA, 99, 16093-16098.

Brouard, S., Otterbein, LE., Anrather, J., Tobiasch, E., Bach, FH., Choi, AM. \& Soares, MP. (2000) Carbon monoxide generated by heme oxygenase 1 suppresses endothelial cell apoptosis. $J$. Exp. Med., 192, 1015-1026.

Campos, M.M., Souza, G.E. \& Calixto, J.B. (1996) Upregulation of B1 receptor mediating des-Arg9-BK-induced rat paw oedema by systemic treatment with bacterial endotoxin. Br. J. Pharmacol., 117, 793-798.

Chen, K., Gunter, K. \& Maines, M.D. (2000) Neurons overexpressing heme oxygenase- 1 resist oxidative stress-mediated cell death. J. Neurochem., 75, 304-313.

Choi, A.M. \& Alam, J. (1996) Heme oxygenase-1: function, regulation, and implication of a novel stress-inducible protein in oxidant-induced lung injury. Am. J. Respir. Cell Mol. Biol., 15, 9-19.

Cirino, G., Cicala, C., Bucci, M.R., Sorrentino, L., Maraganore, J.M. \& Stone, S.R. (1996) Thrombin functions as an inflammatory mediator through activation of its receptor. J. Exp. Med., 183, 821-827.

Clark, J.E., Foresti, R., Sarathchandra, P., Kaur, H., Green, C.J. \& Motterlini, R. (2000) Heme oxygenase-1-derived bilirubin ameliorates postischemic myocardial dysfunction. Am. J. Physiol. Heart Circ. Physiol., 278, H643-651.

Decarie, A., Adam, A. \& Couture, R. (1996) Effects of captopril and Icatibant on bradykinin (BK) and des [Arg9] BK in carrageenan-induced edema. Peptides, 17, 1009-1015.

Dorman, R.B., Bajt, M.L., Farhood, A., Mayes, J. \& Jaeschke, H. (2004) Heme oxygenase-1 induction in hepatocytes and nonparenchymal cells protects against liver injury during endotoxemia. Comp. Hepatol., 14 Suppl 1, S42.

Furuyama, K., Kaneko, K. \& Vargas, P.D. (2007) Heme as a magnificent molecule with multiple missions: heme determines its own fate and governs cellular homeostasis. Tohoku J. Exp. Med., 213, 1-16.

Hou, C., Kirchner, T., Singer, M., Matheis, M., Argentieri, D. \& Cavender, D. (2004) In vivo activity of a phospholipase C inhibitor, 1-(6-((17beta-3-methoxyestra-1,3,5(10)-trien-17yl)amino)hexyl)-1H-pyrrole-2,5-dione (U73122), in acute and chronic inflammatory reactions. J. Pharmacol. Exp. Ther., 309, 697-704.

Igarashi, K., Hoshino, H., Muto, A., Suwabe, N., Nishikawa, S., Nakauchi, H. \& Yamamoto, M. (1998) Multivalent DNA binding complex generated by small Maf and Bach1 as a possible biochemical basis for beta-globin locus control region complex. J. Biol. Chem., 273, 11783-11790.

Igarashi, K. \& Sun, J. (2006) The heme-Bach1 pathway in the regulation of oxidative stress response and erythroid differentiation. Antioxid. Redox. Signal., 8, 107-118.

Keyse, S.M. \& Tyrrell, R.M. (1989) Heme oxygenase is the major
32-kDa stress protein induced in human skin fibroblasts by UVA radiation, hydrogen peroxide, and sodium arsenite. Proc. Natl. Acad. Sci. USA, 86, 99-103.

Kyo, M., Yamamoto, T., Motohashi, H., Kamiya, T., Kuroita, T., Tanaka, T., Engel, J.D., Kawakami, B. \& Yamamoto, M. (2004) Evaluation of MafG interaction with Maf recognition element arrays by surface plasmon resonance imaging technique. Genes Cells., 9, 153-164.

Lee, E.S., Ju, H.K., Moon, T.C., Lee, E., Jahng, Y., Lee, S.H., Son, J.K., Baek, S.H. \& Chang, H.W. (2004) Inhibition of nitric oxide and tumor necrosis factor-alpha (TNF-alpha) production by propenone compound through blockade of nuclear factor (NF)-kappa B activation in cultured murine macrophages. Biol. Pharm. Bull., 27, 617-620.

Lehmann, V., Freudenberg, M.A. \& Galanos, C. (1987) Lethal toxicity of lipopolysaccharide and tumor necrosis factor in normal and D-galactosamine-treated mice. J. Exp. Med., 165, 657-663.

Morikawa, A., Kato, Y., Sugiyama, T., Koide, N., Chakravortty, D., Yoshida, T. \& Yokochi, T. (1999) Role of nitric oxide in lipopolysaccharide-induced hepatic injury in D-galactosaminesensitized mice as an experimental endotoxic shock model. Infect. Immun., 67, 1018-1024.

Morikawa, A., Sugiyama, T., Kato, Y., Koide, N., Jiang, G.Z., Takahashi, K., Tamada, Y. \& Yokochi, T. (1996) Apoptotic cell death in the response of D-galactosamine-sensitized mice to lipopolysaccharide as an experimental endotoxic shock model. Infect. Immun., 64, 734-738.

Motohashi, H., O’Connor, T., Katsuoka, F., Engel, J.D. \& Yamamoto, M. (2002) Integration and diversity of the regulatory network composed of Maf and CNC families of transcription factors. Gene, 294, 1-12.

Nakahira, K., Takahashi, T., Shimizu, H., Maeshima, K., Uehara, K., Fujii, H., Nakatsuka, H., Yokoyama, M., Akagi, R. \& Morita, K. (2003) Protective role of heme oxygenase-1 induction in carbon tetrachloride-induced hepatotoxicity. Biochem. Pharmacol., 66, 1091-1105.

Ni, A., Yin, H., Agata, J., Yang, Z., Chao, L. \& Chao, J. (2003) Overexpression of kinin B1 receptors induces hypertensive response to des-Arg9-bradykinin and susceptibility to inflammation. J. Biol. Chem., 278, 219-225.

Ogawa, K., Sun, J., Taketani, S., Nakajima, O., Nishitani, C., Sassa, S., Hayashi, N., Yamamoto, M., Shibahara, S., Fujita, H. \& Igarashi, K. (2001) Heme mediates derepression of Maf recognition element through direct binding to transcription repressor Bach1. EMBO J., 20, 2835-2843.

Omura, S., Suzuki, H., Toyofuku, M., Ozono, R., Kohno, N. \& Igarashi, K. (2005) Effects of genetic ablation of bach1 upon smooth muscle cell proliferation and atherosclerosis after cuff injury. Genes Cells., 10, 277-285.

Otterbein, L.E., Zuckerbraun, B.S., Haga, M., Liu, F., Song, R., Usheva, A., Stachulak, C., Bodyak, N., Smith, R.N., Csizmadia, E., Tyagi, S., Akamatsu, Y., Flavell, R.J., Billiar, T.R., Tzeng, E., Bach, F.H., Choi, A.M. \& Soares, M.P. (2003) Carbon monoxide suppresses arteriosclerotic lesions associated with chronic graft rejection and with balloon injury. Nat. Med., 9, 183-190.

Oyake, T., Itoh, K., Motohashi, H., Hayashi, N., Hoshino, H., Nishizawa, M., Yamamoto, M. \& Igarashi, K. (1996) Bach proteins belong to a novel family of BTB-basic leucine zipper transcription factors that interact with MafK and regulate transcription through the NF-E2 site. Mol. Cell. Biol., 16, 6083-6095.

Petrache, I., Otterbein, L.E., Alam, J., Wiegand, G.W. \& Choi, A.M. (2000) Heme oxygenase-1 inhibits TNF-alpha-induced apoptosis in cultured fibroblasts. Am. J. Physiol. Lung Cell Mol. Physiol., 278, L312-319.

Poss, K.D. \& Tonegawa, S. (1997a) Heme oxygenase 1 is required for mammalian iron reutilization. Proc. Natl. Acad. Sci. USA., 
94, 10919-10924.

Poss, K.D. \& Tonegawa, S. (1997b) Reduced stress defense in heme oxygenase 1-deficient cells. Proc. Natl. Acad. Sci. USA., 94, 10925-10930.

Sass, G., Soares, MC., Yamashita, K., Seyfried, S., Zimmermann, W.H., Eschenhagen, T., Kaczmarek, E., Ritter, T., Volk, H.D. \& Tiegs, G. (2003) Heme oxygenase-1 and its reaction product, carbon monoxide, prevent inflammation-related apoptotic liver damage in mice. Hepatology, 38, 909-918.

Shibahara, S., Muller, R., Taguchi, H. \& Yoshida, T. (1985) Cloning and expression of cDNA for rat heme oxygenase. Proc. Natl. Acad. Sci. USA, 82, 7865-7869.

Shibahara, S., Muller, R.M. \& Taguchi, H. (1987) Transcriptional control of rat heme oxygenase by heat shock. J. Biol. Chem., 262, 12889-12892.

Shimizu, H., Takahashi, T., Suzuki, T., Yamasaki, A., Fujiwara, T., Odaka, Y., Hirakawa, M., Fujita, H. \& Akagi, R. (2000) Protective effect of heme oxygenase induction in ischemic acute renal failure. Crit. Care Med., 28, 809-817.

Sun, J., Hoshino, H., Takaku, K., Nakajima, O., Muto, A., Suzuki, H., Tashiro, S., Takahashi, S., Shibahara, S., Alam, J., Taketo, MM., Yamamoto, M. \& Igarashi, K. (2002) Hemoprotein Bach1 regulates enhancer availability of heme oxygenase-1 gene. EMBO J., 21, 5216-5224.

Sun, J., Brand, M., Zenke, Y., Tashiro, S., Groudine, M. \& Igarashi, K. (2004) Heme regulates the dynamic exchange of Bach1 and NF-E2-related factors in the Maf transcription factor network. Proc. Natl. Acad. Sci. USA., 101, 1461-1466.

Suzuki, H., Tashiro, S., Hira, S., Sun, J., Yamazaki, C., Zenke, Y., Ikeda-Saito, M., Yoshida, M. \& Igarashi, K. (2004) Heme regulates gene expression by triggering Crm1-dependent nuclear export of Bach1. EMBO J., 23, 2544-2553.

Taketani, S., Kohno, H., Yoshinaga, T. \& Tokunaga, R. (1989) The human 32-kDa stress protein induced by exposure to arsenite and cadmium ions is heme oxygenase. FEBS Lett., 245, 173-176.

Tiegs, G., Wolter, M. \& Wendel, A. (1989) Tumor necrosis factor is a terminal mediator in galactosamine/endotoxin-induced hepatitis in mice. Biochem. Pharmacol., 38, 627-631.

Wagener, FA., Eggert, A., Boerman, OC., Oyen, WJ., Verhofstad, A., Abraham, NG., Adema, G., van Kooyk, Y., de Witte, T. \& Figdor, CG. (2001) Heme is a potent inducer of inflammation in mice and is counteracted by heme oxygenase. Blood, $\mathbf{9 8}$, $1802-1811$.

Wang, M.H., Cox, G.W., Yoshimura, T., Sheffler, L.A., Skeel, A. \& Leonard, E.J. (1994) Macrophage-stimulating protein inhibits induction of nitric oxide production by endotoxin- or cytokinestimulated mouse macrophages. J. Biol. Chem., 269, 14027-14031.

Willis, D., Moore, A.R., Frederick, R. \& Willoughby, D.A. (1996) Heme oxygenase: a novel target for the modulation of the inflammatory response. Nat. Med., 2, 87-90.

Wolf, A.M., Wolf, D., Rumpold, H., Ludwiczek, S., Enrich, B., Gastl, G., Weiss, G. \& Tilg, H. (2005) The kinase inhibitor imatinib mesylate inhibits TNF-\{alpha\} production in vitro and prevents TNF-dependent acute hepatic inflammation. Proc. Natl. Acad. Sci. USA., 102, 13622-13627.

Yachie, A., Niida, Y., Wada, T., Igarashi, N., Kaneda, H., Toma, T., Ohta, K., Kasahara, Y. \& Koizumi, S. (1999) Oxidative stress causes enhanced endothelial cell injury in human heme oxygenase-1 deficiency. J. Clin. Invest., 103, 129-135.

Yang, L., Quan, S. \& Abraham, N.G. (1999) Retrovirus-mediated HO gene transfer into endothelial cells protects against oxidant-induced injury. Am. J. Physiol., 277, L127-133.

Yano, Y., Ozono, R., Oishi, Y., Kambe, M., Yoshizumi, M., Ishida, T., Omura, S., Oshima, T. \& Igarashi, K. (2006) Genetic ablation of the transcription repressor Bach1 leads to myocardial protection against ischemia/reperfusion in mice. Genes Cells, 11, 791-803.

Zenke-Kawasaki, Y., Dohi, Y., Katoh, Y., Ikura, T., Ikura, M., Asahara, T., Tokunaga, F., Iwai, K. \& Igarashi, K. (2007) Heme induces ubiquitination and degradation of the transcription factor Bach1. Mol. Cell. Biol., 27, 6962-6971. 